\title{
Efficacy of furosemide for prevention of exercise-induced pulmonary hemorrhage in Thoroughbred racehorses
}

\author{
Kenneth W. Hinchcliff, BVsc, PhD, Dacvim; Paul S. Morley, DVM, PhD, DAcvim; Alan J. Guthrie, BvSc, PhD
}

\begin{abstract}
Objective-To evaluate the efficacy of furosemide for prevention of exercise-induced pulmonary hemorrhage (EIPH) in Thoroughbred racehorses under typical racing conditions.

Design-Randomized, placebo-controlled, blinded, crossover field trial.

Animals-167 Thoroughbred racehorses.

Procedures-Horses were allocated to race fields of 9 to 16 horses each and raced twice, 1 week apart, with each of the 2 races consisting of the same race field and distance. Each horse received furosemide $(500 \mathrm{mg}, \mathrm{IV})$ before one race and a placebo (saline solution) before the other, with the order of treatments randomly determined. Severity of EIPH was scored on a scale from 0 to 4 after each race by means of tracheobronchoscopy. Data were analyzed by means of various methods of multivariable logistic regression.
\end{abstract}

Results-Horses were substantially more likely to develop EIPH (severity score $\geq 1$; odds ratio, 3.3 to 4.4 ) or moderate to severe EIPH (severity score $\geq 2$; odds ratio, 6.9 to 11.0) following administration of saline solution than following administration of furosemide. In addition, 81 of the $120(67.5 \%)$ horses that had EIPH after administration of saline solution had a reduction in EIPH severity score of at least 1 when treated with furosemide.

Conclusions and Clinical Relevance-Results indicated that prerace administration of furosemide decreased the incidence and severity of EIPH in Thoroughbreds racing under typical conditions in South Africa. (J Am Vet Med Assoc 2009;235:76-82)

$\mathrm{H}$ orse racing is a popular, multimillion-dollar industry worldwide, but reports of injuries and other physical disorders in racehorses have harmed public perceptions of the sport and challenged the economic viability of the racing industry. In addition, controversy has been generated by use of medications that are perceived to affect the performance or well-being of racehorses. One of the foremost concerns in this regard is the occurrence of EIPH and the use of medications in an attempt to prevent it. Factors that make this an important issue include the frequency of EIPH, the importance of the disease in terms of the performance and well-being of horses, and the common use of prophylactic treatments. At least $80 \%$ of racehorses can be expected to develop the condition at some time during their career, ${ }^{1,2}$ approximately $60 \%$ of sudden deaths during racing have been attributed to pulmonary hemorrhage, ${ }^{2}$ severe EIPH has been shown to adversely affect race performance, ${ }^{3}$ and EIPH is believed to adversely affect the overall health of racehorses. ${ }^{4}$ Beyond this,

\begin{tabular}{ll}
\hline & \multicolumn{1}{c}{ AbBREVIATIONS } \\
EIPH & Exercise-induced pulmonary hemorrhage \\
IQR & Interquartile range \\
NHRA & $\begin{array}{l}\text { National Horse Racing Authority } \\
\text { of South Africa }\end{array}$ \\
OR & $\begin{array}{l}\text { Odds ratio } \\
\text { R }\end{array}$ \\
\hline
\end{tabular}

management and treatment of EIPH have a substantial economic impact, with the cost of treating EIPH estimated to exceed $\$ 100$ million annually in the United States alone. ${ }^{4}$

Furosemide is the drug most widely used to prevent EIPH in racehorses and is administered on the day of racing to $>92 \%$ of Thoroughbred racehorses in North America (approx 400,000 doses/y). ${ }^{4,5}$ However, few studies have examined whether furosemide is effective in preventing the development of EIPH, and the studies that have been performed were not conducted

\footnotetext{
From the Faculty of Veterinary Science, University of Melbourne, Melbourne, VIC 3030, Australia (Hinchcliff); the Department of Clinical Sciences, College of Veterinary Medicine and Biomedical Sciences, Colorado State University, Fort Collins, CO 80523 (Morley); and the Faculty of Veterinary Science, University of Pretoria, Onderstepoort 0110, Gauteng, Republic of South Africa (Guthrie).

All authors contributed equally to this study.

Supported by the National Horseracing Authority of South Africa, Phumelela Gaming and Leisure (Pty) Ltd, TecMed (Pty) Ltd, Racing South Africa (Pty) Ltd, the Grayson-Jockey Club Research Foundation, the Racing Medication and Testing Consortium, the Thoroughbred Racing Trust of South Africa, and private donors.

The authors thank Graeme Hawkins, Elvarde van Zyl, Eddie Smith, Rob de Kock, Dr. Duncan MacDonnald, Dr. Dale Wheeler, Dr. Cindy Harper, Dr. Melvyn Quan, Dr. John Grewar, Dr. Patrick Page, Dr. Rosie Gerber, Dr. Cynthia Donnellan, Dr. Robin Moore, Dr. Karin Kruger, Stellest de Villiers, Anette Nel, Ilse Vorster, Roehan Sutherland, Taelo Sibi, Dr. Rick Sams, and Dr. Schalk de Kock for technical, logistic, and administrative assistance.

Address correspondence to Dr. Hinchcliff.
} 
under actual racing conditions. Given this lack of evidence and the finding that furosemide can improve the performance of Thoroughbred racehorses, ${ }^{6}$ the use of furosemide to prevent EIPH remains controversial. The purpose of the study reported here, therefore, was to evaluate the efficacy of furosemide for the prevention of EIPH in Thoroughbred racehorses racing under typical conditions.

\section{Materials and Methods}

Study design-The study was conducted as a randomized, placebo-controlled, crossover field trial. All study participants, including data analysts, were blinded to treatment assignments until statistical analyses related to the primary outcome were completed. The study was conducted at the Vaal Racing and Training facility in Free State Province, Republic of South Africa, between November 20 and 28, 2007, and the study protocol was approved by the institutional animal care and use committees of the University of Pretoria and Colorado State University. For all horses participating in the study, the owner or his or her designee (ie, the trainer) provided informed consent.

Experimental protocol-In an attempt to include horses broadly representative of all horses racing in South Africa, the study was announced at public meetings of trainers, during television programs devoted to horse racing, via racing Web sites, in text messages to trainers, and in advertisements in the local print media inviting owners and trainers to nominate horses for inclusion in the study. Horses considered eligible for participation were Thoroughbred racehorses registered with the NHRA and trained by licensed trainers. Horses were enrolled without knowledge of whether they had previously had EIPH, with the exception that horses with a history of epistaxis during racing or training that had been documented by a veterinarian or steward employed by the NHRA were excluded. At the time horses were nominated for inclusion in the study, the owner or trainer was asked to indicate the specific race or races (eg, 1,300-m race with colts and geldings that had merit ratings $\leq 76$ ) designated for the study during which the horse would be allowed to race.

Horses accepted for inclusion in the study were assigned to race fields on the basis of age, sex, and race record by a professional handicapper who also assigned handicap weights, with each race field consisting of 9 to 16 horses. Enrolled horses raced twice, 7 days apart, with each of the 2 races consisting of the same race field (with the exception of horses withdrawn from the study prior to the second race) and same race distance. Horses carried the same weight, were ridden by the same jockey, started from the same barrier stall, and wore identical tack during the 2 races. Races were run over turf according to the rules of racing of the NHRA, with the exception that administration of furosemide or a placebo prior to each race was permitted for purposes of the present study. In accordance with NHRA rules, blood and urine samples were obtained from selected horses after each race and tested for prohibited medications, including NSAIDs. Owners of horses included in the study were paid a participation fee of
R2,000 on completion of the second race. In addition, prize money was paid to the owners of horses that finished first (R28,750), second (R9,200), third $(R 4,600)$, fourth $(\mathrm{R} 2,300)$, or fifth $(\mathrm{R} 1,150)$ in each race. Prior to each race, trainers were allowed to withdraw (scratch) horses from the race in accordance with the standard rules of racing. Horses that were withdrawn prior to the first race were not allowed to participate in the second race.

Trainers were required to bring participating horses to the racetrack 4.5 hours before the scheduled start time of the race in which they were to compete. As each horse arrived at the track, study personnel confirmed the identity of the horse by checking for a microchip and applied an adhesive tag with a unique identifying number to the mane. Horses were then weighed, placed in stalls, and attended by their grooms. Access to food and water was denied from 4 hours prior to racing until after a tracheobronchoscopic examination was performed following completion of the race. Thirty minutes before the scheduled start of the race, horses were again weighed and moved to the saddling enclosure.

Four hours ( \pm 5 minutes) before the scheduled start of the race, horses were treated with furosemide or a placebo. Each horse received furosemide before one race and a placebo before the other. Treatment order (furosemide prior to the first race and placebo prior to the second race vs placebo prior to the first race and furosemide prior to the second race) was randomly determined by assigning a computer-generated random number to every horse prior to the first race. The first half of each field, as determined by these random numbers, was assigned to receive furosemide prior to the first race and a placebo prior to the second race. The second half of each field was assigned to the opposite treatment order.

Randomization and treatment assignment were performed by an investigator who was not involved in administering any treatments on race days. Individual doses of furosemide $(500 \mathrm{mg}$ ) and a placebo solution were prepared for all horses prior to the initiation of the study. Each syringe contained $10 \mathrm{~mL}$ of solution, and syringes were labeled with horse identification number, race number, and race day. The furosemide solution that was used for the present study had a slight yellow color. Therefore, the placebo solution consisted of saline $(0.9 \% \mathrm{NaCl})$ solution to which a vitamin $\mathrm{B}$ complex solution ${ }^{\mathrm{b}}(0.1 \mathrm{~mL} / 1,000 \mathrm{~mL}$ of saline solution) had been added as a coloring agent. Because each 10-mL dose of the placebo solution contained only $0.0001 \mathrm{~mL}$ of the vitamin B complex solution, it was considered unlikely to have had any clinically important biological effect, and vitamin B complex solution was not added to the furosemide solution. Furosemide and placebo solutions were administered by IV injection into a jugular vein. Blood samples were collected 15 minutes after treatments were administered and tested for furosemide concentration to verify that the correct treatment had been given.

All races started within 4 minutes of the scheduled start times. At the end of each race, horses were returned to the parade ring, where they were examined by veterinary officials from the NHRA and their tack 
was removed. A tracheobronchoscopic examination was then performed. All tracheobronchoscopic examinations were performed by one or the other of 2 teams consisting of 2 veterinarians and 2 lay assistants each. Individuals performing the tracheobronchoscopic examinations were experienced in the procedure, were provided information on the general study protocol, and were specifically asked to thoroughly examine the pharynx, larynx, and trachea to the level of its bifurcation. However, they were blinded to treatment group assignment. All examinations were directly overseen by one of the authors (KWH) and were digitally recorded. After completion of the tracheobronchoscopic examination, horses were released to the care of their trainers.

Maximum environmental temperature on race days ranged from $21.1^{\circ}$ to $27.6^{\circ} \mathrm{C}\left(70.0^{\circ}\right.$ to $\left.81.7^{\circ} \mathrm{F}\right)$, and minimum environmental temperature ranged from $18.9^{\circ}$ to $25.6^{\circ} \mathrm{C}\left(66.0^{\circ}\right.$ to $\left.78.1^{\circ} \mathrm{F}\right)$. Maximum humidity ranged from $18 \%$ to $73 \%$, and minimum humidity ranged from $14 \%$ to $55 \%$. Wind speed during the times that horses raced ranged from 3.4 to $9.2 \mathrm{~m} / \mathrm{s}$. A total of $2 \mathrm{~mm}$ of rain fell during the time that horses raced on the first race day; $4.2 \mathrm{~mm}$ of rain fell on the last of the 4 race days, although this fell after completion of the last race that day.

Assessment of EIPH severity-Digital recordings of each of the tracheobronchoscopic examinations were reviewed by 3 individuals experienced in endoscopic examination of the airway in horses. Individuals scoring the recordings were blinded to identity of the horses and treatment group assignments.

Scoring of EIPH severity was performed by all 3 individuals concurrently, with the digital recording displayed on a large-screen television. Each individual was asked to assign a score from 0 to 4 for severity of EIPH on the basis of a previously reported validated scoring system. ${ }^{7}$ Individual scores were then discussed, and if necessary, the examination was reviewed to obtain a consensus score, with consensus scores used in all data analyses.

Data analysis-During design of the study, sample size calculations were performed with standard commercial software. ${ }^{c}$ For these calculations, it was assumed that if furosemide were efficacious, the proportion of horses with an EIPH score $\geq 2$ would be $\leq$ $10 \%$ following treatment with furosemide, compared with an assumed baseline prevalence of $20 \%$ when horses were not treated with furosemide, ${ }^{3}$ and that the mean $\rho$ value for repeated observations among subjects would be 0.4 . When the $\alpha$ error rate was set at 0.05 , sample size calculations indicated that approximately 150 horses would need to complete both arms of the study to achieve a $\beta$ error rate of 0.2 . Assuming that a maximum of $20 \%$ of the study subjects would be withdrawn between the first and second arms of the study and that race fields would achieve a minimum of $90 \%$ subscription through the use of typical race enrollment methods, we calculated that 12 races with a maximum of 16 horses starting in each race would be required for each arm of the study. No rules for stopping the study or interim analysis of results were put in place.

The primary study outcome was the score for severity of EIPH as determined by means of tracheobronchos- copy. Continuous data were summarized as median and IQR because data were generally not normally distributed, with the exception that differences between preand posttreatment body weights of horses were normally distributed and were summarized as mean and SE and elapsed times between the start of racing and tracheobronchoscopy were normally distributed and were summarized as mean and SD. For horses that completed both arms of the study, the EIPH severity score after treatment with furosemide was compared with severity score after treatment with placebo, and the difference between scores was summarized as mean and SD; the Wilcoxon signed rank test was used to determine whether the median difference between scores was significantly different from 0 . The Wilcoxon rank sum test was used to compare ordinal and continuous data between groups, and the $\chi^{2}$ test of homogeneity was used to compare categorical data between groups. The Bowker symmetry test was used to compare paired EIPH severity scores for horses that completed both arms of the study.

Scores for endoscopic severity of EIPH could not be analyzed in their native form (ie, scores of 0 to 4 ) by means of proportional odds, multinomial logistic regression because assumptions of proportionality were not met. Therefore, scores were dichotomized (0 vs 1 to 4 and 0 or 1 vs 2 to 4 ) to allow analysis by means of logistic regression. Because various methods have been proposed for analysis of data from crossover studies with binomial outcomes, ${ }^{8-10}$ mixed-effects, repeated-measures fixed-effects, and conditional logistic regression models were all used to analyze dichotomized scores. Horse identity was nested within treatment sequence in these analyses to account for random and repeated effects. The primary exposure of interest was treatment (furosemide vs placebo); however, sex, race distance, age, and treatment sequence (furosemide prior to the first race and placebo prior to the second race vs placebo prior to the first race and furosemide prior to the second race) were also evaluated as fixed effects in mixed-effects and repeated-measures modeling. It was not possible to analyze sex, race distance, or age in conditional logistic regression models, as there were no differences in these exposures for paired observations. Age ( $\leq 3$ years old vs $\geq 4$ years old) and race distance $(1,000,1,300$, or $1,600 \mathrm{~m})$ were analyzed as categorical fixed effects. Exposure variables were analyzed for simple associations with outcome and were included in models with the primary exposure of interest (treatment). Confounding was investigated in multivariable models by evaluating the change in parameter estimates that occurred when variables were included or excluded from the model. Confounding was considered to be present when estimates changed by $\geq 20 \%$. Effect modification was investigated by inclusion of first-order interaction terms. Treatment sequence was included as a random or repeated effect in each model, regardless of whether a significant association could be identified, when treatment sequence was analyzed as a fixed effect. This was considered a conservative method of accounting for incomplete washout, ${ }^{8-10}$ even though incomplete washout was not expected.

It was not possible to analyze data on an intent-totreat basis because tracheobronchoscopy is not routinely 
performed after racing and occurrence of EIPH was not known for horses that did not participate. Therefore, data were analyzed on a per-protocol basis. However, use of repeated-measures and mixed-effects logistic regression allowed inclusion of data for horses that only completed the first race (as opposed to requiring that horses complete both arms of the study to be included in analyses), which provided some assurance that missing data for horses that were withdrawn (scratched) did not strongly bias the conclusions of the study.

Analyses were performed with commercial software. ${ }^{\mathrm{d}}$ A priori, values of $P \leq 0.05$ were determined to be significant.

\section{Results}

A total of 328 horses were nominated for inclusion in the study. Of these, 193 (77 females and 116 stallions and geldings) were enrolled in the study by the professional handicapper. Of the 193 horses enrolled in the study, 155 competed in both races, 12 competed only in the first race, and 26 did not compete in either race (Table 1). Horses that participated in the study were from 40 stables (median, 3.5 horses/stable; range, 1 to 14 horses/stable). Twenty-three trainers withdrew at least 1 horse from a study race. Demographic characteristics of horses that did not compete in either race did not differ significantly from characteristics of horses that competed in at least 1 race (Table 2 ).

Two horses that competed in both races would not allow tracheobronchoscopy to be performed after either race because of their fractious nature, and 1 horse would not allow tracheobronchoscopy to be performed after the second race. Mean \pm SD time between the start of racing and tracheobronchoscopy was $41.6 \pm 5.9$

Table 1-Details of racing conditions for Thoroughbred racehorses enrolled in a study of the efficacy of furosemide for prevention of EIPH.

\begin{tabular}{|c|c|c|c|c|c|c|c|}
\hline $\begin{array}{l}\text { Race } \\
\text { day }\end{array}$ & Race No. & Distance (m) & Class & $\begin{array}{c}\text { Horses } \\
\text { nominated }\end{array}$ & $\begin{array}{l}\text { Horses } \\
\text { enrolled* }\end{array}$ & $\begin{array}{c}\text { Raced } \\
\text { in first } \\
\text { race }\end{array}$ & $\begin{array}{l}\text { Raced } \\
\text { in second } \\
\text { race }\end{array}$ \\
\hline $\begin{array}{l}\text { A } \\
A \\
A \\
A \\
A \\
A\end{array}$ & $\begin{array}{l}1 \\
2 \\
3 \\
4 \\
5 \\
6\end{array}$ & $\begin{array}{l}1,300 \\
1,300 \\
1,300 \\
1,600 \\
1,600 \\
1,600\end{array}$ & $\begin{array}{l}\text { Maiden fillies } \\
\text { Maiden colts and geldings } \\
\text { Maiden colts and geldings } \\
\text { Maiden colts and geldings } \\
\text { Maiden colts and geldings } \\
\text { Maiden fillies }\end{array}$ & $\begin{array}{l}38 \\
32 \\
31 \\
27 \\
26 \\
43\end{array}$ & $\begin{array}{l}18 \\
17 \\
18 \\
14 \\
14 \\
18\end{array}$ & $\begin{array}{l}15 \\
14 \\
15 \\
14 \\
13 \\
15\end{array}$ & $\begin{array}{l}12 \\
14 \\
14 \\
13 \\
11 \\
13\end{array}$ \\
\hline $\begin{array}{l}\text { B } \\
\text { B } \\
\text { B } \\
\text { B } \\
\text { B } \\
\text { B }\end{array}$ & $\begin{array}{l}1 \\
2 \\
3 \\
4 \\
5 \\
6\end{array}$ & $\begin{array}{l}1,000 \\
1,000 \\
1,300 \\
1,300 \\
1,600 \\
1,600\end{array}$ & $\begin{array}{l}\text { Fillies and mares (merit ratings } \leq 68 \text { ) } \\
\text { Colts and geldings (merit ratings } \leq 72 \text { ) } \\
\text { Colts and geldings (merit ratings } \leq 76 \text { ) } \\
\text { Fillies and mares (merit ratings } \leq 72 \text { ) } \\
\text { Fillies and mares (merit ratings } \leq 68 \text { ) } \\
\text { Colts and geldings (merit ratings } \leq 68 \text { ) } \\
\text { Total }\end{array}$ & $\begin{array}{r}22 \\
37 \\
56 \\
39 \\
35 \\
38 \\
328\end{array}$ & $\begin{array}{r}13 \\
18 \\
18 \\
16 \\
12 \\
17 \\
193\end{array}$ & $\begin{array}{r}9 \\
16 \\
15 \\
15 \\
12 \\
14 \\
\mathbf{1 6 7}\end{array}$ & $\begin{array}{r}9 \\
16 \\
13 \\
14 \\
12 \\
14 \\
\mathbf{1 5 5}\end{array}$ \\
\hline
\end{tabular}

Table 2-Demographic characteristics of Thoroughbred racehorses enrolled in a study of the efficacy of furosemide for prevention of EIPH.

\begin{tabular}{|c|c|c|c|c|}
\hline Variable & $\begin{array}{l}\text { Nominated but } \\
\text { not enrolled }\end{array}$ & $\begin{array}{c}\text { Raced at least } \\
\text { once }\end{array}$ & $\begin{array}{l}\text { Enrolled but did } \\
\text { not race }\end{array}$ & $P$ value \\
\hline No. of horses & 135 & 167 & 26 & NA, NA \\
\hline Age & $4(3-5)$ & $4(3-4)$ & $4(4-5)$ & $0.39,0.12^{*}$ \\
\hline Sex & & & & $0.86,0.34 \dagger$ \\
\hline Stallion & 9 & 13 & 0 & \\
\hline Gelding & 69 & 88 & 15 & \\
\hline Female & 57 & 66 & 11 & \\
\hline Assigned weight $(\mathrm{kg})$ & NA & $57(56-58)$ & $58(55-58)$ & $N A, 0.45^{*}$ \\
\hline Merit rating $\ddagger$ & $65(55-72)$ & $65(59-69)$ & $58(54-65)$ & $0.28,0.02^{*}$ \\
\hline \multicolumn{5}{|l|}{ Lifetime No. } \\
\hline Starts & $12(5-21)$ & $10(3-22)$ & $12(8-21)$ & $0.35,0.19^{*}$ \\
\hline First-place finishes & $1(0-2)$ & $0(0-1)$ & $1(0-1)$ & $0.06,0.79^{*}$ \\
\hline $\begin{array}{l}\text { Second-and third- } \\
\text { place finishes }\end{array}$ & $2(0-5)$ & $2(0-4)$ & $2(1-5)$ & $0.50,0.15^{*}$ \\
\hline Finishes earning money & $4(2-9)$ & $4(0-9)$ & $4.5(3-8)$ & $0.56,0.35^{*}$ \\
\hline Lifetime earnings $(\mathrm{R})$ & $\begin{array}{c}536,250 \\
(220,000-1,018,700)\end{array}$ & $\begin{array}{c}60,850 \\
(23,000-111,745)\end{array}$ & $\begin{array}{c}48,750 \\
(23,550-94,490)\end{array}$ & $0.21,0.42^{*}$ \\
\hline \multicolumn{5}{|c|}{$\begin{array}{l}\text { Data are given as median (IQR) or number of horses. } P \text { values are given as the } P \text { value for comparisons } \\
\text { between horses that were nominated but not enrolled and horses that were enrolled, followed by the } P \text { value } \\
\text { for comparisons between horses that raced at least once and horses that were enrolled but did not race. } \\
{ }^{*} P \text { value from Wilcoxon rank sum test. } † P \text { value from } \chi^{2} \text { test of homogeneity. } \text { Excludes maidens. } \\
\text { NA = Not applicable. }\end{array}$} \\
\hline
\end{tabular}


minutes when horses were treated with furosemide and $42.1 \pm 6.0$ minutes when horses were treated with saline solution. These values were not significantly $(P=$ 0.63) different.

Scores for endoscopic severity of EIPH ranged from 1 to 4 in 89 of 161 (55.3\%) horses after administration of furosemide and in 125 of 156 (80.1\%) horses after administration of saline solution (Figure 1); these proportions were significantly $(P<$ $0.001)$ different. For the 152 horses examined after both races, 87 (57.2\%) had EIPH (ie, severity score $\geq 1$ ) after administration of furosemide, whereas 120 (78.9\%) had EIPH after administration of saline solution (Table 3 ). None of the horses had severe EIPH (ie, a score of 3 or 4) after administration of furosemide. Overall, 81 of the 120 (67.5\%) horses that had EIPH after administration of saline solution had a reduction in EIPH severity score of at least 1 when treated with furosemide. Mean \pm SD reduction in EIPH severity score after furosemide administration in the 120 horses that had EIPH after administration of placebo was $0.63 \pm 0.08$; median reduction in EIPH severity score was significantly $(P<0.001)$ different from 0 .

Results of mixed-effects, repeated-measures fixed-effects, and conditional logistic regression analyses all indicated that horses had significantly lower odds of developing EIPH (ie, severity score $\geq 1$ ) or moderate to severe EIPH (ie, severity score $\geq 2$ ) following administration of furosemide, compared with odds following administration of saline solution (Table 4). Horses were 3.3 to 4.4 times as likely to have an EIPH score $\geq 1$ following administration of saline solution than they were following administration of furosemide and were 6.9 to 11.0 times as likely to have an EIPH score $\geq 2$ following administration of saline solution than they were following administration of furosemide.

Although results of mixed-effects and repeatedmeasures fixed-effects logistic regression suggested that horses that were $\geq 4$ years old were more likely to develop EIPH (ORs, 1.8 and 1.9, respectively; $P=0.04$ and 0.07 , respectively), no effect modification (ie, an interaction between age and treatment) was detected, and age did not appear to be a confounding variable in these analyses. Development of EIPH was also not associated with sex $(P=0.30$ and 0.38 , respectively), distance raced $(P=0.38$ and 0.99 , respectively), or treatment sequence ( $P=0.69$ and 0.99 , respectively) in these analyses.

Mean \pm SE weight loss during the 4 hours prior to the start of the race was $12.7 \pm 0.33 \mathrm{~kg}(27.9 \pm$ $0.73 \mathrm{lb})$ when horses were given furosemide $(\mathrm{n}=160)$ and $5.4 \pm 0.28 \mathrm{~kg}(11.9 \pm 0.62 \mathrm{lb})$ when horses were given saline solution (155). These values were significantly $(P<0.001)$ different. There was no association between weight loss and development of EIPH, even when controlling for treatment $(P \geq 0.50)$.

Analysis of blood samples collected 15 minutes after administration of furosemide or placebo confirmed the presence of furosemide in all horses after administration of furosemide and in none of the horses after administration of the placebo.

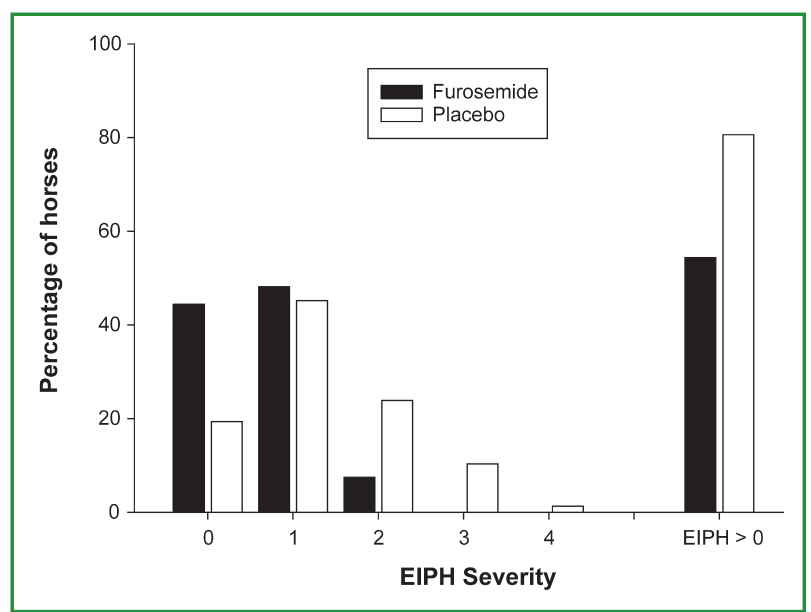

Figure 1-Distribution of scores for endoscopic severity of EIPH in Thoroughbred horses that raced following administration of furosemide (500 mg, IV; $\mathrm{n}=161$ ) or a placebo (saline solution; 156).

Table 3-Cross-classification of scores for endoscopic severity of EIPH following racing in 152 Thoroughbred racehorses competing twice under similar conditions each time, except that furosemide (500 mg, IV) was administered prior to one race and a placebo (saline solution) was administered prior to the other.

\begin{tabular}{|c|c|c|c|c|c|c|}
\hline \multirow{2}{*}{$\begin{array}{l}\text { EIPH score } \\
\text { when } \\
\text { administered } \\
\text { furosemide }\end{array}$} & \multicolumn{5}{|c|}{$\begin{array}{l}\text { EIPH score when } \\
\text { administered placebo }\end{array}$} & \multirow[b]{2}{*}{ Total } \\
\hline & 0 & 1 & 2 & 3 & 4 & \\
\hline 0 & 21 & 32 & 10 & 2 & 0 & 65 \\
\hline 1 & 10 & 32 & 21 & 11 & 1 & 75 \\
\hline 2 & 1 & 3 & 4 & 3 & 1 & 12 \\
\hline 3 & 0 & 0 & 0 & 0 & 0 & 0 \\
\hline 4 & 0 & 0 & 0 & 0 & 0 & 0 \\
\hline Total & 32 & 67 & 35 & 16 & 2 & 152 \\
\hline
\end{tabular}

Table 4-Results of logistic regression analysis of EIPH severity scores for Thoroughbred racehorses enrolled in a study of the efficacy of furosemide for prevention of EIPH.

\begin{tabular}{|c|c|c|c|}
\hline Logistic regression analysis method & $\mathbf{O R}$ & $95 \% \mathrm{Cl}$ & $P$ value \\
\hline $\begin{array}{l}\text { Development of EIPH (ie, severity } \\
\text { score } \geq 1 \text { ) } \\
\text { Mixed-effects } \\
\text { Repeated-measures fixed-effects } \\
\text { Conditional }\end{array}$ & $\begin{array}{l}3.4^{*} \\
3.3^{*} \\
4.4 \dagger\end{array}$ & $\begin{array}{l}2.0-5.7 \\
2.1-5.2 \\
2.2-8.8\end{array}$ & $\begin{array}{l}<0.001 \\
<0.001 \\
<0.001\end{array}$ \\
\hline $\begin{array}{l}\text { Development of moderate to severe } \\
\text { EIPH (ie, severity score } \geq 2 \text { ) } \\
\text { Mixed-effects } \\
\text { Repeated-measures fixed-effects } \\
\text { Conditional }\end{array}$ & $\begin{array}{r}7.1^{*} \\
6.9^{*} \\
11.0 \dagger\end{array}$ & $\begin{array}{l}3.6-14.1 \\
3.7-13.0 \\
4.0-30.3\end{array}$ & $\begin{array}{l}<0.001 \\
<0.001 \\
<0.001\end{array}$ \\
\hline $\begin{array}{l}{ }^{*} \text { Odds ratio was adjusted for age. } \\
\text { age, because this variable did not differ } \\
\mathrm{CI}=\text { Confidence interval. } \\
\text { Odds ratios represent the odds th } \\
\text { following administration of a placeb } \\
\text { with the odds that they would develo } \\
\text { ministration of furosemide }(500 \mathrm{mg} \text {, IV }\end{array}$ & $\begin{array}{l}\text { horses } \\
\text { (saline } \\
\text { ElPH }\end{array}$ & $\begin{array}{l}\text { was not a } \\
\text { paired obs } \\
\text { would dev } \\
\text { solution), }\end{array}$ & $\begin{array}{l}\text { djusted for } \\
\text { ervations. } \\
\text { elop EIPH } \\
\text { compared } \\
\text { erace ad- }\end{array}$ \\
\hline
\end{tabular}

\section{Discussion}

Results of the present study indicated that prerace administration of furosemide decreased the incidence and severity of EIPH in Thoroughbreds racing under 
typical conditions in South Africa. Specifically, horses were substantially more likely to develop EIPH (severity score $\geq 1$; OR, 3.3 to 4.4 ) or moderate to severe EIPH (severity score $\geq 2$; OR, 6.9 to 11.0) following administration of saline solution than following administration of furosemide, and the estimated proportion (unadjusted for repeated measures or confounding) of horses that developed EIPH (ie, severity score $\geq 1$ ) following administration of furosemide (89/161 [55.3\%]) was significantly lower than the estimated proportion that did following administration of saline solution $(125 / 156[80.1 \%])$. In addition, 81 of the 120 (67.5\%) horses that had EIPH after administration of saline solution had a reduction in EIPH severity score of at least 1 when treated with furosemide.

Important strengths of the present study include the large number of horses examined, the evaluation of horses after standard race conditions, and the use of horses from a population expected to be at risk for developing EIPH (ie, Thoroughbred racehorses in active training and racing). Because various methods have been recommended for analysis of data from crossover studies, we elected to use mixed-effects, repeated-measures fixed-effects, and conditional logistic regression to analyze our data, and results of all 3 analyses were consistent. The strong association between furosemide administration and protection against development of EIPH made it unlikely that unidentified confounding factors or other biases were solely responsible for this effect. The use of a crossover study design enhanced the statistical power of the study over that associated with a parallel-group study design. ${ }^{11}$

Examination of drug effects under actual conditions of use has long been recognized as the best measure of efficacy in human medicine, with randomized, controlled, clinical trials considered to provide the highest degree of evidence for efficacy. ${ }^{12}$ However, such trials can be difficult to perform in veterinary medicine, and we are not aware of any previous such studies that have addressed the effects of various preventive measures on the development of EIPH in racehorses.

Results of the present study provide strong evidence that furosemide can help prevent the development of EIPH in Thoroughbred racehorses. As such, its use in racehorses might be justifiable, assuming that other regulatory and policy issues important to the integrity of the sport are adequately addressed.

The mechanism by which furosemide prevents EIPH is unclear, and the present study was not designed to address this issue. It has been speculated that furosemide-induced reductions in body weight are indicative of reductions in body water and intravascular fluid volume and that these reductions in body water and intravascular fluid volume attenuate the exercise-induced increase in pulmonary arterial blood pressure typically associated with exercise, with a consequent reduction in the incidence of alveolar capillary rupture and decreased hemorrhage. ${ }^{13-15}$ The amount of weight lost by horses in the present study after furosemide administration was consistent with the amount of weight loss in horses administered furosemide under experimental conditions. ${ }^{16-18}$ However, weight loss does not appear to be directly related to the mechanism by which furosemide prevents EIPH, in that we did not identify an association between amount of weight lost and prevention of EIPH in the present study. We have previously shown that EIPH adversely affects the performance of racehorses and that treatment with furosemide improves race performance, ${ }^{3,6}$ and results of the present study would seem to suggest that the improved performance associated with furosemide could potentially be attributed to prevention or mitigation of EIPH.

For the present study, we believed that evaluating a large number of horses under actual racing conditions was important because previous studies ${ }^{13,19}$ have used experimental models (eg, horses running on a treadmill) that might not reflect racing conditions, had low statistical power because of low numbers of horses, or had limitations in study design or statistical analysis that may have affected their results. Two previous studies ${ }^{1,20}$ have examined the effect of furosemide in racehorses under field conditions, although with differing conclusions regarding efficacy. However, neither study was conducted as a randomized, controlled trial, and the data analysis in one of these studies ${ }^{21}$ has been criticized.

An important concern with crossover studies is that the time between arms of the study (ie, the washout period) must be sufficiently long to preclude any residual effects associated with the previous treatment. In the present study, we elected to use a washout period of 7 days on the basis of the reported short elimination half-life of furosemide in horses ( $\beta$ half-life, 24 minutes; $\gamma$ half-life, 177 minutes) and the brief (1-hour) diuretic effect of the drug. ${ }^{22}$ The fact that we did not detect furosemide in any of the blood samples collected 15 minutes after administration of saline solution suggested that the washout period was adequate. In addition, there was no evidence that treatment order had an effect on the results of our statistical analyses. Finally, even if there had been a carryover effect in horses that had been treated with furosemide first, this would have acted to make it more difficult to identify a difference between the 2 treatments.

Furosemide reduces mucociliary clearance in humans and causes bronchodilation in ponies with recurrent airway obstruction. ${ }^{23,24}$ It is possible, therefore, that furosemide did not actually decrease alveolar bleeding in the present study but simply decreased the rostral progression of blood from the alveoli, diminishing the amount of blood in the trachea at the time of endoscopic examination and resulting in an artifactually low EIPH severity score. Alternatively, bronchodilation secondary to furosemide administration might have favored rostral movement of blood and made the endoscopic score appear worse than it would have been had furosemide not been administered. We believe that the magnitude of either of these potentially conflicting effects is likely to be small in horses without recurrent airway obstruction and bronchoconstriction and would have been unlikely to have materially affected the overall conclusions of the present study.

The present study was performed in South Africa for logistic reasons. However, South Africa has a wellregulated racing industry with horses comparable to those racing in other parts of the world. We believe, therefore, that our results can be generalized to other 
racing jurisdictions, particularly given the relative genetic homogeneity of Thoroughbred racehorses, ${ }^{25}$ the similarity in training techniques and racing conditions throughout the world, ${ }^{26}$ and the characteristics of horses included in our study. Although racing and training conditions in other parts of the world do differ from those in South Africa in minor respects, we do not have any evidence that any of these differences have been demonstrated to have an impact on the frequency or severity of EIPH. Therefore, we believe that results of the present study are relevant to horses racing worldwide.

a. Salix, Intervet SA (Pty) Ltd, Isando, South Africa.

b. Kryovite B Co Super, Kyron Laboratories (Pty) Ltd, Benrose, South Africa.

c. PASS 2007, Number Cruncher Statistical Systems, Kayesville, Utah. d. SAS, version 9.2, SAS Institute Inc, Cary, NC.

\section{References}

1. Birks EK, Shuler KM, Soma LR, et al. EIPH: postrace endoscopic evaluation of Standardbreds and Thoroughbreds. Equine Vet $J$ Suppl 2002;34:375-378.

2. Boden LA, Charles JA, Slocombe RF, et al. Sudden death in racing Thoroughbreds in Victoria, Australia. Equine Vet J 2005;37:269-271.

3. Hinchcliff KW, Jackson MA, Morley PS, et al. Association between exercise-induced pulmonary hemorrhage and performance in Thoroughbred racehorses. J Am Vet Med Assoc 2005;227:768-774.

4. Hinchcliff KW. Exercise-induced pulmonary hemorrhage, in Proceedings. Annu Meet Am Assoc Equine Pract 2005;51:342-347.

5. Heller B. Run baby run: what every owner, breeder and handicapper should know about Lasix in racehorses. Neenah, Wis: Russell Meerdink, 2002.

6. Gross DK, Morley PS, Hinchcliff KW, et al. Effect of furosemide on performance of Thoroughbreds racing in the United States and Canada. J Am Vet Med Assoc 1999;215:670-675.

7. Hinchcliff KW, Jackson MA, Brown JA, et al. Tracheobronchoscopic assessment of exercise-induced pulmonary hemorrhage in horses. Am J Vet Res 2005;66:596-598.

8. Brown H, Prescott R. Applied mixed models in medicine. 2nd ed. London: J Wiley, 2006.

9. Littell R. SAS for mixed models. 2nd ed. Cary, NC: SAS Institute Inc, 2006.

10. Stokes ME, Daves CS, Koch GG. Categorical data analysis using the SAS system. 2nd ed. Cary, NC: SAS Institute Inc, 2000.

11. Senn S. Cross-over trials in clinical research. New York: J Wiley, 2002.
12. Phillips B. Levels of evidence. Available at: www.cebm.net/index. aspx?o=1025\#levels. Accessed May 11, 2009.

13. Lester G, Clark C, Rice B, et al. Effect of timing and route of administration of furosemide on pulmonary hemorrhage and pulmonary arterial pressure in exercising Thoroughbred racehorses. Am J Vet Res 1999;60:22-28.

14. Olsen SC, Coyne CP, Lowe BS, et al. Influence of furosemide on hemodynamic response during exercise in horses. Am J Vet Res 1992;53:742-747.

15. Zawadzkas XA, Sides RH, Bayly WM. Is improved high speed performance following frusemide administration due to diuresis-induced weight loss or reduced severity of exercise-induced pulmonary haemorrhage? Equine Vet J Suppl 2006;36:291-293.

16. Bayly WM, Slocombe RF, Schott HC II, et al. Effect of intravenous administration of furosemide on mass-specific maximal oxygen consumption and breathing mechanics in exercising horses. Am J Vet Res 1999;60:1415-1422.

17. Hinchcliff KW, McKeever KH. Fluid administration attenuates the haemodynamic effect of frusemide in running horses. Equine Vet J 1998;30:246-250.

18. Hinchcliff KW, McKeever KH, Muir WW III, et al. Effect of furosemide and weight carriage on energetic responses of horses to incremental exertion. Am J Vet Res 1993;54:1500-1504.

19. Geor RJ, Ommundson L, Fenton G, et al. Effects of an external nasal strip and frusemide on pulmonary haemorrhage in Thoroughbreds following exercise. Equine Vet J 2001;33:577-584.

20. Pascoe JR, McCabe AE, Franti CE, et al. Efficacy of furosemide in the treatment of exercise-induced pulmonary hemorrhage in Thoroughbred racehorses. Am J Vet Res 1985;46:2000-2003.

21. Clarke A. Comments on furosemide and exercise-induced pulmonary hemorrhage in horses (lett). Am J Vet Res 1989;50:2183-2184.

22. Chay S, Woods WE, Rowse K, et al. The pharmacology of furosemide in the horse. V. Pharmacokinetics and blood levels of furosemide after intravenous administration. Drug Metab Dispos 1983;11:226-231.

23. Broadstone RV, Robinson NE, Gray PR, et al. Effects of furosemide on ponies with recurrent airway obstruction. Pulm Pharmacol 1991;4:203-208.

24. Kondo CS, Macchionne M, Nakagawa NK, et al. Effects of intravenous furosemide on mucociliary transport and rheological properties of patients under mechanical ventilation. Crit Care 2002;6: $81-87$.

25. Cunningham EP, Dooley JJ, Splan RK, et al. Microsatellite diversity, pedigree relatedness and the contributions of founder lineages to Thoroughbred horses. Anim Genet 2001;32:360-364.

26. O'Sullivan CB, Lumsden JM. Veterinary aspects of training and racing Thoroughbred race horses. In: Hinchcliff KW, Kaneps AJ, Geor RJ, eds. Equine sports medicine and surgery: basic and clinical sciences of the equine athlete. London: WB Saunders Co, 2004;1051-1073. 